\title{
CGIAR RESEARCH ON
} AGRICULTURAL INSURANCE: PAST ACHIEVEMENTS AND FUTURE RESEARCH PRIORITIES

\author{
Berber Kramer, Francisco Ceballos, Peter Hazell, \\ and Anne G. Timu
}

\section{KEY MESSAGES}

- A recent external review of IFPRI's research on agricultural insurance found that, since 2009, IFPRI has made important contributions to the literature on factors constraining farmers' demand for agricultural insurance and on gender inclusiveness of insurance and, since 2015, has focused more specifically on developing new forms of insurance that can reduce basis risk at the farm level and make insurance more attractive to farmers.

- IFPRI's work on flexible insurance contracts, picture-based insurance, and bundling agricultural insurance with credit, seeds, and other agricultural services shows that well-designed insurance can significantly improve on standard index products, increase demand among smallholders, and lead to greater use of bundled inputs like improved seeds and climate-smart farming practices.

- ILRI's long-term success with its index-based livestock insurance (IBLI) product illustrates that an action-oriented approach aimed at working with strong implementing partners on the ground ensures that, when a product is successful, it has the potential to scale up quickly, leading to significant development impacts.

- Important knowledge gaps that warrant further CGIAR research include:

1) segmenting product design and marketing strategies for different target groups, such as sustainable commercial insurance and inclusive insurance; 2 ) the value and optimal design of programs and policies to remove tail-end catastrophic risks, and of insurance more broadly within a more holistic risk management framework; and 3 ) cost-benefit analyses around the net social benefits of insurance subsidies, and how these subsidies can best be designed and targeted to achieve their purposes. 
Farm households face a host of market and production risks that make their incomes volatile from year to year, undermine their food security, and make them hesitant to adopt new technologies or undertake new investments that might increase their long-term productivity and household welfare. Major shocks can also lead to loss of assets and episodic humanitarian crises that require large-scale relief interventions. Climate change is worsening the problem for many farmers, increasing both the frequency and severity of some disasters.

One consequence of this serious and growing problem has been an increase in public spending on disaster assistance, spurring a more proactive interest from governments, and echoed in the international development community, in setting up tools such as agricultural insurance to manage risk ex ante and thus increase the predictability of budget flows by shifting relief expenditures to insurance subsidies and disaster preparedness. In addition to the hope that agricultural insurance could reduce farmers' need for disaster assistance, other objectives of an insurance-based approach include facilitating the development of rural finance, extending insurance to often excluded groups like poor and women farmers, and more generally helping promote agricultural development and farmers' adaptation to climate change. Interest in achieving these objectives has in turn spawned a surge in technological and institutional innovations and new policy practices by practitioners, academics, and organizations such as CGIAR.

\section{CGIAR contributions}

In addition to the development of climate-smart and resilient farming technologies and practices, several CGIAR centers have undertaken research on technological and institutional innovations to promote and increase the effectiveness of agricultural insurance for smallholder farmers.

\section{Early research on crop insurance (2009- 2015)}

The International Food Policy Research Institute (IFPRI) has undertaken research on agricultural in- surance since 2009. A recent external review of this research found that, between 2009 and 2015, IFPRI made important and well-cited contributions to the literature on factors constraining farmers' demand for agricultural insurance (Hazell and Timu 2021). This included helping to clarify the impact of basis risk, liquidity constraints, trust, premium prices, financial literacy, and having experienced a payout on farmers' demand for insurance products. In the quest for inclusiveness, IFPRI also made important contributions toward quantifying differences in insurance demand by gender and in evaluating the potential of group insurance.

Based on early findings, IFPRI then started focusing more specifically on developing new forms of insurance that can reduce basis risk at the farm level and make insurance more attractive to farmers. One approach, flexible index insurance, relies on offering simplified, independent insurance products covering a range of specific risks in different calendar months, which can be combined to form tailored insurance portfolios that better match farmers' risk profiles than a standard contract designed for an average farm in the region (Ceballos and Robles 2020). Another approach is gap insurance or audits, which allow either individual farmers or a larger insurance unit (e.g., a farmers group) to appeal to the insurance company when the index does not trigger by presenting evidence of substantial onthe-ground damage (from local weather stations or crop-cut estimates of average yields) due to an insured risk (Flatnes et al. 2018; Berhane et al. 2015).

\section{Testing innovations in crop insurance (2015 and beyond)}

More recently, IFPRI has developed picture-based insurance (PBI), an approach that uses smartphone pictures of insured fields for damage estimation and claims settlement (Ceballos, Kramer, and Robles 2019). PBI can be used to provide evidence of localized damage for gap insurance, but it also has potential as a new approach to operationalize indemnity insurance remotely at a reduced cost. This line of research has also given rise to work on comparing and combining different datasets, such as weather data, near-surface images, and traditional 
satellite imagery, that can aid in better designing more traditional index products. Related research on using machine learning and artificial intelligence to improve automatic damage detection and the overall quality of insurance products, especially PBI, also looks promising. ${ }^{1}$

As a next step, IFPRI has begun investigating distribution models that bundle agricultural insurance with credit (also called risk-contingent credit, RCC), improved seeds, and other agricultural services. Such bundling is intended to enhance the value of insurance, deepen impacts on farm productivity and welfare, enable financial institutions to expand lending to smallholders, and, if adequately designed, make insurance more gender-responsive and socially inclusive. Various studies are underway to test this approach and determine to what extent de-risking agriculture can help different types of smallholder farmers and different members of their families.

IFPRI has also contributed to capacity strengthening through this research and its choice of partners. Case study evidence shows that local capacity to implement and improve insurance programs often remains after IFPRI has exited a pilot project (Hazell and Timu 2021). A notable feature of IFPRI's insurance work since 2012 is that it has gone beyond initial experimental research and evolved into sustained programs with implementing partners who have a commercial interest in the insurance. This has happened in Uruguay with the Ministry of Livestock, Agriculture, and Fisheries (MGAP) and the State Insurance Bank (BSE), is ongoing in Kenya with ACRE Africa and Equity Bank, in Ethiopia with the R4 Rural Resilience Scheme, and in India with HDFC ERGO General Insurance, Dvara E-Registry, and the national crop insurance scheme or Pradhan Mantri Fahsal Bima Yojana (PMFBY).

IFPRI's work shows that well-designed insurance can significantly improve on standard index products, increase demand among smallholders, and lead to greater use of bundled inputs like improved seeds and climate-smart farming practices.
Moreover, an action-oriented approach aimed at working with strong implementing partners on the ground ensures that, when a product is successful, it has the potential to scale up quickly, leading to significant development impacts. This has already happened in Uruguay, where a flexible index insurance program that IFPRI helped design for horticultural farms is still operating successfully after eight years (Hazell and Timu 2021).

\section{Livestock insurance}

In addition to IFPRI's work, the International Livestock Research Institute (ILRI) has undertaken pioneering research on livestock insurance since 2010, focusing initially on the arid and semi-arid lands of Kenya. Rooted in a research-for-development agen$\mathrm{da}$, an index-based livestock insurance (IBLI) product was developed to help pastoralists avoid significant losses in drought years, from which it would be otherwise difficult to recover (Chantarat et al. 2012). Payments are triggered at the local level based on satellite observations of a normalized difference vegetation index (NDVI), which is highly correlated with livestock losses in drought years (Jensen et al. 2016). IBLI was initially piloted in Marsabit county in Kenya and has now matured into a micro-insurance scheme in which the insurance is sold directly to pastoralists by private insurance companies on a voluntary basis throughout most of the arid and semi-arid areas of Kenya and in some pastoral regions in Ethiopia.

Several factors contributed to the establishment of IBLI as a beacon product in the index insurance landscape. The availability of rich historical data on livestock mortality enabled the initial research needed to calibrate a model based on satellite data for tracking such losses. In addition, the pilots conducted in Kenya and Ethiopia were carefully monitored over several years through ILRI-led data collection activities that included a panel survey of about 1,400 households, allowing for evidence-based development of the program over time. Studies based on these panel data show that pastoralists' purchase of IBLI led to strategic livestock accumulation, better

1 For more information and related research see https://www.ifpri.org/project/PBInsurance 
livestock husbandry practices, and overall better marketing decisions, resulting in higher animal productivity (Jensen et al. 2017). The project involved long-lasting partnerships with private insurers, universities, research organizations, and government departments for initial product design, testing, and final implementation. It is arguably one of the most successful research-for-development projects on agricultural insurance undertaken within CGIAR, a success that is attributable in part to a long funding timeline that enabled the research team to complete rigorous and long-term impact assessments and feed results back into the program's design as needed.

\section{Research on agricultural insurance across CGIAR}

Other CGIAR centers have also worked on agricultural insurance in recent years. Most of this work has focused on demand-side issues and on bundling insurance with agricultural inputs like improved seeds and climate-smart farming practices. CIMMYT, ICRISAT, and IRRI, for example, have all experimented with bundling index insurance with drought- or stress-tolerant seed varieties, but unlike IFPRI they have worked with standard forms of index insurance and have not investigated $\mathrm{PBI}$ or more flexible weather index contracts. IWMI has also developed flood insurance for irrigated farming areas (Amarnath et al. 2021).

The CGIAR Research Program on Policy, Institutions, and Markets (PIM) has provided funding for IFPRI's research on agricultural insurance since 2012, and the CGIAR Research Program on Climate Change and Food Security (CCAFS) has provided funding to other CGIAR centers to support their work on agricultural insurance, especially that related to climate shocks. The CCAFS website also provides a platform for presenting study results, syntheses, and good practice guidelines. Nearly all the supported work relates to demand-side issues for farmers, especially smallholders, and technological innovations for reducing basis risk in product design (for example, improvements in the use of remote sensing data and crop modeling).

\section{Knowledge gaps and future research priorities}

Despite the progress made to date with agricultural insurance and the contributions of the CGIAR centers and programs, some important knowledge gaps remain that seem likely to become more important with climate change and thus warrant further research by CGIAR.

Sustainable commercial insurance: More research is needed into the development and refinement of new and emerging innovations that can make agricultural insurance more attractive and more accessible to smallholders on a commercial basis. Two promising developments in particular stand out that could help transform insurance markets: 1) increased availability of granular data for designing contracts and reducing basis risk from advances in remote sensing and on-the-ground crop monitoring through smartphone pictures; and 2) bundling of insurance with various other value-adding services, such as drought-tolerant seeds, credit, or extension (Kramer et al. 2021). While there are grounds for optimism, it is still not known how far insurance can scale, and expecting full coverage seems unwarranted given the large protection gaps in much better developed industries, such as property and casualty or life insurance (Howard 2018).

Inclusive insurance: On its own, the development of sustainable commercial insurance markets does not enable many poor and women-headed households to access insurance. Additional interventions are required, often through an intermediary like a nongovernmental organization (NGO) or a safety net program that can address the complex targeting problems involved in designing and delivering insurance for these groups. A limitation of past research is that it rarely distinguishes product design needs for commercial farmers from those for subsistence farmers. Inclusive insurance may require permanent subsidies that, while justifiable on equity grounds, need to be appropriately targeted. Overall, there is an urgent need for randomized controlled trials and other rigorous studies to estimate costs and benefits of insurance programs that 
are explicitly designed to reach, benefit, and empower more excluded groups.

Insurers and intermediaries: Most research to date has focused on making insurance more attractive to farmers, without focusing on making insurance attractive to private insurers or the intermediaries needed for bundling insurance with credit and other agricultural services. As a result, governments, donor agencies, and NGOs have been the ones initiating new insurance programs for smallholders, with private agents playing subsidiary roles. More research is needed to better understand why the private sector does not see insurance as a more attractive business proposition, and what changes or nudges are needed to encourage them to be more venturesome. This might also involve deepening the research on meso-insurance that can be sold directly to intermediary organizations.

Catastrophic risks: Many catastrophic (or so-called tail-end) risks are too expensive for farmers to insure, yet their frequency and severity is increasing in many regions due to climate change. In this context, the public sector faces the choice between responding to shocks ex post through emergency relief programs that can be too slow and difficult to fund at short notice or helping finance the removal of these risks from the agriculture sector ex ante through provision of catastrophe insurance, which would inevitably entail subsidies. Thus, the real question is whether heavily subsidized catastrophe insurance for farmers would improve on other forms of disaster assistance or safety net transfers in terms of overall cost savings, encouraging better ex ante risk management, improving the speed at which disaster assistance is delivered, reducing future dependence on disaster assistance, or crowding-in insurance for residual risks. Very limited evidence exists in this area, highlighting insurance-based financing of disaster assistance as a key priority for future research.

Public policy: The public sector plays key roles in scaling up agricultural insurance, and significant amounts of public money are spent on insurance subsidies in many developing countries - more than US\$11 billion a year in total, according to one recent study (GIZ 2021). While subsidies might often be warranted (for example, for insuring excluded groups or catastrophic risks), many governments also use insurance subsidies for other purposes too (Hazell and Varangis 2019). Yet, there have been few comprehensive cost-benefit analyses of subsidized insurance programs to guide public spending decisions. IFPRI is collecting the data for such analyses in some of its ongoing pilot programs, but there is urgent need for more research studies and cost-benefit analyses of the net benefits of insurance subsidies and how they can best be designed and targeted to achieve their purposes. In some cases, comparisons between the cost-benefit ratio of using insurance subsidies and alternative policies, such as safety net programs, disaster assistance, or credit guarantees, are needed.

More comprehensive risk management: Most studies on agricultural insurance focus on production risk, ignoring the larger risk management problem that farmers face. Many important hazards (such as price or marketing risks, postharvest risks, and an array of non-agricultural risks) cannot be insured against or it is too expensive to do so. In addition, farmers already use a broad portfolio of formal and informal tools to manage and cope with risk - where insurance is at best just part of the solution. In such a context, farmers with multiple pressing needs may not see sufficient value in limited risk management instruments, making it easy to overestimate individual farmers' demand for insurance. Overall, additional research is needed on holistic risk management strategies that include coverage against other agricultural and non-agricultural risks; and on quantifying the value added of insurance compared to other financial instruments that farmers (especially more commercially oriented ones) can use to partially manage their risks. In this regard, we are optimistic that some of the technological developments that are helping to create new opportunities to strengthen the quality of agricultural insurance may also help transform other risk management aids, such as credit products and forward price contracts. 


\section{Conclusions}

CGIAR is starting a new generation of initiatives in 2021, many of which include thematic pillars and specific activities involving de-risking agricultural production through insurance. This brief has identified several research priorities in carrying out these research agendas. In particular, these initiatives should carefully consider the differences between sustainable commercial insurance and inclusive insurance, and the different target groups and appropriate marketing strategies for those types of products. Moreover, our understanding of what are the best approaches for interventions that can reduce tail-end catastrophic risks needs to be improved, and analyses conducted of how much value insurance can add within a more holistic risk management framework. Finally, given the large role of the public sector, and the inevitable increase in the frequency and severity of catastrophic events and their dire effect on vulnerable farmers, more research studies are needed to quantify the net social benefits of insurance subsidies, and to determine how they can best be designed and targeted to achieve their purposes.

\section{About the authors}

Berber Kramer is a senior research fellow and Francisco Ceballos is a research fellow in the Markets, Trade, and Institutions Division of the International Food Policy Research Institute (IFPRI). Peter Hazell is a research fellow emeritus with IFPRI. Anne Gesare Timu is a graduate research assistant at the University of Nebraska-Lincoln.

\section{Acknowledgments}

This brief is a summary of research supported by the CGIAR Research Program on Policies, Institutions, and Markets (PIM), led by the International Food Policy Research Institute. The IFPRI research reviewed in this brief received additional support from the CGIAR Research Program on Climate Change, Agriculture and Food Security (CCAFS), the CGIAR Platform for Big Data in Agriculture, the International initiative for Impact Evaluation (3ie), the Natural Environment Research Council (NERC), the Netherlands-CGIAR research program on seed systems development funded by the Dutch research council (NWO-WOTRO), Cultivate Africa's Future Phase 2 funded by the Australian Centre for International Agriculture Research (ACIAR) and the International Development Research Centre (IDRC), and the USAID Feed the Future Innovation Lab for Markets, Risk and Resilience. We are grateful for insights from Harold Alderman, Neha Kumar, and participants in a PIM webinar on innovations in agricultural insurance.

\section{References}

Afshar, M.H., T. Foster, T.P. Higginbottom, B. Parkes, K. Hufkens, S. Mansabdar, F. Ceballos, and B. Kramer. 2021. "Improving the Performance of Index Insurance Using Crop Models and Phenological Monitoring." Remote Sensing 13: 924.

Amarnath, G., R.P.S. Malik, and A. Taron. 2021. Scaling Up Index-based Flood Insurance (IBFI) for Agricultural Resilience and Flood-Proofing Livelihoods in Developing Countries. IWMI Research Report 180. Colombo: International Water Management Institute. 
Berhane, G., S. Dercon, R.V. Hill, W. Bank, and A.S. Taffesse. 2015. "Formal and Informal Insurance: Experimental Evidence from Ethiopia." Presented at the International Conference of Agricultural Economists, Milan, Aug. 8-14.

Ceballos, F., and M. Robles. 2020. "Demand Heterogeneity for Index-Based Insurance: The Case for Flexible Products." Journal of Development Economics 146: 102515.

Ceballos, F., B. Kramer, and M. Robles. 2019. "The Feasibility of Picture-Based Insurance (PBI): Smartphone Pictures for Affordable Crop Insurance." Development Engineering 4: 100042.

Chantarat, S., A.G. Mude, C.B. Barrett, and M.R. Carter. 2012. "Designing Index-Based Livestock Insurance for Managing Asset Risk in Northern Kenya." Journal of Risk and Insurance 80: 205-237.

Flatnes, J.E., M.R. Carter, and R. Mercovich. 2018. "Improving the Quality of Index Insurance with a Satellite-Based Conditional Audit Contract." Working Paper, University of California-Davis.

GIZ. 2021. Innovations and Emerging Trends in Agricultural Insurance. Update. Bonn and Eschborn, Germany.

Hazell, P., and P. Varangis. 2020. "Best Practices for Subsidizing Agricultural Insurance." Global Food Security 25: 100326.

Hazell, P., and A.G. Timu. 2021 forthcoming. "Review and Synthesis of IFPRI's PIM-funded Program of Work on Agricultural Insurance, 2012-2020." IFPRI Discussion Paper. International Food Policy Research Institute, Washington, DC.

Howard, L.S. 2018. "Insurance Protection Gap Is Growing Global Problem; Swiss Re, RenRe \& WTW Comment." Insurance Journal, January 17.

Jensen, N.D., C.B. Barrett, and A.G. Mude. 2016. "Index Insurance Quality and Basis Risk: Evidence from Northern Kenya." American Journal of Agricultural Economics 98: 1450-1469. doi:10.1093/ajae/ aaw046.

Jensen, N.D., C.B. Barrett, and A.G. Mude. 2017. "Cash Transfers and Index Insurance: A Comparative Impact Analysis from Northern Kenya." Journal of Development Economics 129: 14-28.

Kramer, B., P. Hazell, H. Alderman, F. Ceballos, N. Kumar, and A.G. Timu. 2021. "Is Agricultural Insurance Fulfilling Its Promise for the Developing World?" IFPRI Discussion Paper 2057. IFPRI, Washington, DC.

This publication has been prepared as an output of the CGIAR Research Program on Policies, Institutions, and Markets (PIM) led by IFPRI and has not been independently peer reviewed. Any opinions expressed here belong to the author(s) and are not necessarily representative of or endorsed by IFPRI, PIM, or CGIAR.

For more information, please refer to PIM reports, visit www.pim.cgiar.org or contact Frank Place, PIM Director (f.place@cgiar.org).

Photo credits: AgriFin

(C) 2021 International Food Policy Research Institute (IFPRI). This publication is licensed for use under a Creative Commons Attribution 4.0 International License (CC BY 4.0). 